\title{
TWO YEAR HOSPITAL BASED STUDY ON RHINOSPORIDIOSIS IN AND AROUND DHANBAD DISTRICT, JHARKHAND, INDIA
}

\author{
Bejoy Chand Banerjee1, Binay Kumar Singh², Raj Kumar Prasad ${ }^{3}$, Ravi Shankar ${ }^{4}$, Pramod Kumar 5 \\ 1 Professor and HOD, Department of Pathology, Patliputra Medical College and Hospital, Dhanbad, Jharkhand, India. \\ ${ }^{2}$ Associate Professor, Department of Microbiology, Patliputra Medical College and Hospital, Dhanbad, Jharkhand, India. \\ ${ }^{3}$ Associate Professor, Department of Pathology, Patliputra Medical College and Hospital, Dhanbad, Jharkhand, India. \\ ${ }_{4}^{4}$ Tutor, Department of Pathology, Patliputra Medical College and Hospital, Dhanbad, Jharkhand, India. \\ 5Tutor, Department of Biochemistry, Patliputra Medical College and Hospital, Dhanbad, Jharkhand, India.
}

\section{ABSTRACT}

\section{BACKGROUND}

Rhinosporidium seeberi is an organism responsible for Rhinosporidiosis. Most of the time, it will cause infection to nasal mucosa, whereas disseminated infection can also be seen in some cases. Highest incidence of Rhinosporidiosis has been reported from India and Sri Lanka. The presumed mode of infection from the natural aquatic habitat of $R$. seeberi is through the traumatised epithelium. Characteristically, rhinosporidium lesions in the nasal passages are polypoidal, granular, red in colour due to pronounced vascularity with a surface containing yellowish pin head-sized spots which represent underlying mature sporangia. The definitive diagnosis of rhinosporidiosis is by histopathology on biopsied tissues.

\section{MATERIALS AND METHODS}

We have conducted a laboratory based observational study in Patliputra Medical College Hospital (Department of Microbiology and Pathology), Dhanbad, Jharkhand, from January 2016 to December 2017. Clinical samples were collected from suspected cases of Rhinosporidiosis. All specimens were subjected to standard haematoxylin and eosin (H and E) staining.

\section{RESULTS}

Among the suspected cases, $18 \%$ were diagnosed as Rhinosporidiosis. We found that males were commonly infected compared to females, which were $77 \%$ and $23 \%$ respectively. Nasal obstruction was common symptoms, which were observed in $83 \%$ of patients. It was seen that $91 \%$ of patients were from rural background with agriculture and outdoor manual labour work. All the patients were having habit to take bath in pond and low education standards.

\section{CONCLUSION}

Rhinosporidiosis was seen in notable number from this region. That may be due to habit of taking bath in stagnant pond water. Patient education is needed to improve hygiene levels and outdoor bathing should be strictly discouraged in these populations to prevent disease.

\section{KEY WORDS}

Rhinosporidiosis, Haematoxylin and Eosin Staining, Nasal Obstruction.

HOW TO CITE THIS ARTICLE: Banerjee BC, Singh BK, Prasad RK, et al. Two year hospital based study on rhinosporidiosis in and around Dhanbad District, Jharkhand, India. J. Evolution Med. Dent. Sci. 2018;7(22):2651-2653, DOI: 10.14260/jemds/2018/596

\section{BACKGROUND \\ Rhinosporidiosis is a chronic granulomatous mucocutaneous} infection that commonly affects the mucous membranes of the nose and nasopharynx. Disseminated cases have been reported in India and other parts of the world. Clinically, the disease is characterised as slow-growing tumour like masses in nasal cavity, leading to cause nasal obstruction and epistaxis. Disease is endemic in India, Srilanka, South America and Africa.[1] Rhinosporidium seeberi is a fungus belonging to class mesomycetozoea responsible for causing rhinosporidiosis. Morphologically, Rhinosporidium seeberi has a mature stage that consists of large, thick-walled spherical

'Financial or Other Competing Interest': None.

Submission 16-04-2018, Peer Review 10-05-2018,

Acceptance 17-05-2018, Published 28-05-2018.

Corresponding Author:

Dr. Ravi Shankar,

Tutor,

Department of Pathology,

Patliputra Medical College and Hospital,

Dhanbad, Jharkhand, India.

E-mail: ravirimsran02@gmail.com

DOI: $10.14260 /$ jemds $/ 2018 / 596$ structures called 'sporangia' containing smaller 'sporangiospores.' First case of rhinosporidiosis was reported by O'Kinealy in 1903 in India. The definitive diagnosis of rhinosporidiosis depends on histopathology examination of standard haematoxylin and eosin ( $\mathrm{H}$ and $\mathrm{E}$ ) staining of biopsy tissues, which shows multiple budding sporangia containing smaller sporangiospores, entrenched in fibrovascular stroma infiltrated with chronic inflammatory cells.[2] Present study were carried out to evaluate the incidence of Rhinosporidiosis in Dhanbad district region.

\section{MATERIALS AND METHODS}

This is a laboratory based observational study conducted in Patliputra Medical College Hospital (Department of Microbiology and Pathology), Dhanbad, Jharkhand. For a period of 2 years from January 2016 to December 2017, all the suspected cases of Rhinosporidiosis attending OPD were included. Detailed clinical data regarding age, sex and clinical presentations were collected. CT scan of affected area were studied and patients were sent to routine laboratory investigations for operative fitness. ${ }^{[3]}$ Tissue mass, which were removed after surgery were collected. All specimens were subjected to standard haematoxylin and eosin ( $\mathrm{H}$ and $\mathrm{E})$ 
staining. Special fungal stains like Gomori methenamine silver (GMS) and periodic acid-Schiff (PAS) were also done for selective clinical specimens.

\section{Inclusion Criteria}

1. Clinically suspected cases of Rhinosporidiosis.

2. Patients of both sexes and all age group.

\section{Exclusion Criteria}

Patients not able to provide biopsy material or FNAC.

\section{RESULTS}

A total number of 271 nasal masses were collected, in that 48 (18\%) were diagnosed as rhinosporidiosis based on $\mathrm{H}$ and $\mathrm{E}$ staining which were characterised by presence of large, thickwalled spherical structures called 'sporangia' containing smaller 'sporangiospores' [Figure 1]. Among the diagnosed cases, 37 (77\%) were male and $11(23 \%)$ were female. Most of the cases were diagnosed in 0 - 15 and 16 - 30 years of age groups individual in both sexes, which were $35 \%$ and $27 \%$ respectively in male, $6 \%$ and $15 \%$ respectively in female [Table 1]. During nasal cavity examination hyperplastic polypoid lesions were seen in most of the patients. Nasal obstruction was common symptoms, which were observed in $83 \%$ followed by epistaxis in $71 \%$ of patients [Table 2 ].

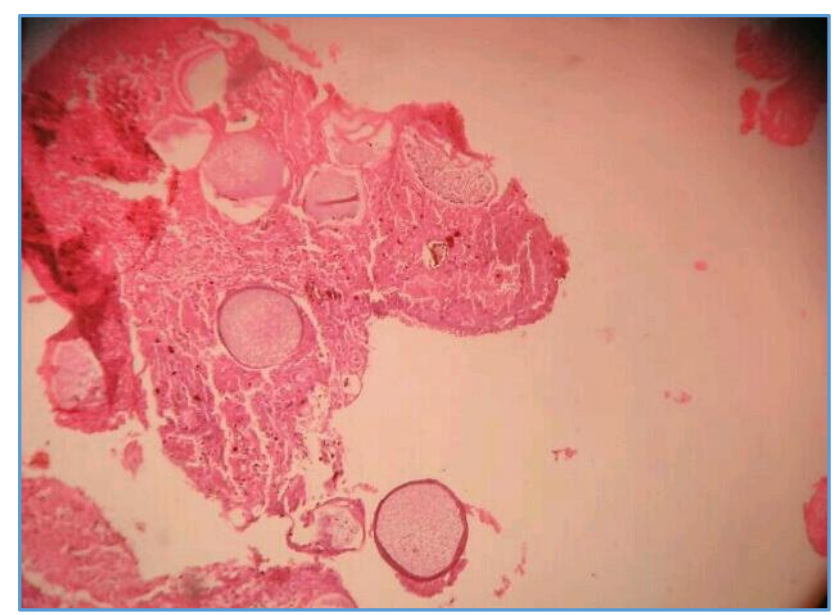

Figure 1. H and E Staining, indicating presence of Cysts

\begin{tabular}{|c|c|c|c|c|c|c|}
\hline \multirow{2}{*}{ Gender } & \multicolumn{5}{|c|}{ Age } & \multirow{2}{*}{ Total } \\
\cline { 2 - 6 } & $0-15$ & $16-30$ & $31-45$ & $46-60$ & $>60$ & \\
\hline Female & 3 & 7 & 1 & 0 & 0 & 11 \\
\hline Male & 17 & 13 & 4 & 3 & 0 & 37 \\
\hline Total & $\mathbf{2 0}$ & $\mathbf{2 0}$ & $\mathbf{5}$ & $\mathbf{3}$ & $\mathbf{0}$ & $\mathbf{4 8}$ \\
\hline Table 1. Gender and Age Distribution of 48 Diagnosed \\
Cases \\
\hline
\end{tabular}

\begin{tabular}{|c|c|c|}
\hline Symptoms & No. of Patients & Percentage \\
\hline Nasal obstruction & 37 & $83 \%$ \\
\hline Epistaxis & 35 & $71 \%$ \\
\hline Nasal discharge & 30 & $52 \%$ \\
\hline \multicolumn{2}{|c|}{ Table 2. Distribution of Common Symptoms } \\
\hline
\end{tabular}

Most of the patients (91\%) were from rural background with agriculture and outdoor manual labour work. The sociocultural background of all the patients were community practice of pond bathing and low education standards.

\section{DISCUSSION}

Previously, similar type of study was not conducted from this geographical area. By conducting the present study, we had made an attempt to know the prevalence of rhinosporidiosis in Dhanbad district of Jharkhand state. Study indicated that diseases seen in a notable number in these area, which were $18 \%$ among the suspected cases of rhinosporidiosis. Result presented in the present study indicated that rhinosporidiosis were more common in males compared to females. We also found that most of the cases were diagnosed in 0 - 15 and 16 - 30 years of age group patients, which were $35 \%$ and $27 \%$ respectively in male and $6 \%$ and $15 \%$ respectively in female. And nasal obstruction were common symptoms, which were observed in $83 \%$ of cases. Study by Saha A et al and Mahmud S et al also reported that males were more commonly infected, which were $79 \%$ and $76 \%$ respectively.[4,5] A similar study from West Bengal indicated that no more differences were observed between male and female rhinosporidiosis cases, which were $57 \%$ and $43 \%$ respectively. In comparison to present study they found less number of male rhinosporidiosis cases, which were $77 \%$ and $57 \%$ respectively.[6] Two different study from India indicated that 21 - 30 years' age group of individuals were commonly infected compared to other age group individuals, which were $38 \%$ and $30 \%$ respectively. Compared to our result, they found slight different results.[7,8] In compression to present study researcher from Bihar found similar type of clinical finding, which was nasal obstruction followed by epistaxis. ${ }^{[4]}$ Our study have shown that most of the patients (91\%) were belonging to rural residential areas and occupational background of all the patients were agriculture. And we also found that socio-cultural background of all the patients were community practice of pond bathing. In comparison to present study, similar results were observed in a study from Bihar.[9] Present study findings suggest that person with nasal mass and practice of pond bathing with poor hygiene, Rhinosporidium seeberi infection can be the primary cause. However, among the negative cases differential diagnosis must be followed for inverted papilloma and non-invasive fungal sinusitis.

\section{CONCLUSION}

Causative pathogen of rhinosporidiosis cannot be grown successfully over artificial culture media in routine diagnostic laboratory. So, diagnosis solely depends on histopathology of clinical material. The occurrence of rhinosporidiosis is more common in India and in Sri Lanka due to poor hygienic practices and habit of pond bathing. Our study also supports the hypothesis of transmission due to ground water. Patient education is also needed to improve hygiene levels and outdoor bathing should be strictly discouraged in these populations to prevent disease.

\section{REFERENCES}

[1] Sarkar S, Panja S, Bandyopadhyay A, et al. Rhinosporidiosis of parotid duct presenting as consecutive bilateral facial swelling: a rare case report and literature review. Journal of Clinical and Diagnostic Research 2016;10(3):PD14-PD16.

[2] Arseculeratne SN. Recent advances in rhinosporidiosis and Rhinosporidium seeberi. Indian Journal of Medical Microbiology 2002;20(3):119-31. 
[3] Prabhu SM, Irodi A, Khiangte HL, et al. Imaging features of rhinosporidiosis on contrast CT. Indian J Radiol Imaging 2013;23(3):212-18.

[4] Saha A, Mukherjee M, Sircar B. Rhinosporidiosis in three northern districts of West Bengal and two adjacent districts of Bihar - study of 116 cases. J Evolution Med Dent Sci 2017;6(3):155-60.

[5] Mahmud S, Haque $\mathrm{R}$, Mamum AA, et al. A clinicopathological study of Rhinosporidiosis. Bangladesh J Otorhinolaryngol 2015;21(2):94-6.

[6] Sinha A, Phukan JP, Bandyopadhyay G, et al. Clinicopathological study of rhinosporidiosis with special reference to cytodiagnosis. J Cytol 2012;29(4):246-9.
[7] Guru RK, Pradhan DK. Rhinosporidiosis with special reference to extra nasal presentation. Journal of Evolution of Medical and Dental Sciences 2014;3(22):6189-99.

[8] Manonmony S, Renjit RE, Philip JT, et al. Rhinosprodiosis: analysis of cases presenting to a tertiary care hospital in rural Kerala. International Journal of Biomedical Research 2015;6(6):416-20.

[9] Majumdar AB, Biswas D, Paul SS, et al. Rhinosporidiosis: a clinicopathological study from a rural tertiary health care centre, Bihar, India. Int J Adv Med 2014;1(3):213-16. 